\title{
Erratum to: Diet Versus Phylogeny: a Comparison of Gut Microbiota in Captive Colobine Monkey Species
}

\author{
Vanessa L. Hale ${ }^{1}$ (1) - Chia L. Tan ${ }^{2} \cdot$ Kefeng Niu $^{3,4}$ - Yeqin Yang ${ }^{3} \cdot$ Rob Knight $^{5,6}$ • \\ Qikun Zhang ${ }^{7} \cdot$ Duoying $\mathrm{Cui}^{8} \cdot$ Katherine R. Amato ${ }^{9}$
}

Published online: 11 September 2017

(C) Springer Science+Business Media, LLC 2017

Erratum to: Microb Ecol (2017)

https://doi.org/10.1007/s00248-017-1041-8

The original version of this article listed an incorrect affiliation for author Chia L. Tan. The correct affiliation is listed below: LVDI International, San Marcos, CA 92078, USA

The online version of the original article can be found at https://doi.org/ 10.1007/s00248-017-1041-8

Vanessa L. Hale

vreynolds@gmail.com

1 Microbiome Program, Mayo Clinic, 200 First St. SW, Rochester, MN 55905, USA

2 LVDI International, San Marcos, CA 92078, USA

3 Fanjingshan National Nature Reserve Administration, Tongren, China

4 Department of Life Sciences and Systems Biology, University of Turin, 10123 Turin, Italy

5 Department of Pediatrics, University of California San Diego, La Jolla, CA 92093, USA

6 Department of Computer Science and Engineering, University of California San Diego, La Jolla, CA 92093, USA

7 Zhejiang Institute of Microbiology, Hangzhou, Zhejiang, China

8 Beijing Key Laboratory of Captive Wildlife Technologies, Beijing Zoo, Beijing 100044, China

9 Department of Anthropology, Northwestern University, Evanston, IL 60208, USA 